\title{
A Meta-Analysis of Enjoyment Effect on Technology Acceptance: The Moderating Role of Technology Conventionality
}

\author{
Nour El Shamy \\ McMaster University \\ elshamyn@mcmaster.ca
}

\author{
Khaled Hassanein \\ McMaster University \\ hassank@mcmaster.ca
}

\begin{abstract}
Recent advancements in Information and Communication Technology lead to the development of affordable, novel, out of the ordinary, and unconventional information technology artifacts. Such innovative technologies including virtual reality, wearable technology, and robots; feature unique human-computer interfaces, untraditional hardware designs, enable unique and atypical affordances, and provide their users with unprecedented experiences. As these artifacts become more pervasive, it is important to understand whether established Information Systems theories apply to this new paradigm. This metaanalysis introduces the definition of technology conventionality and investigates its moderating role on the effect of perceived enjoyment on users' behavioural intention to use the technology with the aim of contrasting the effect sizes across conventional and unconventional technologies. Findings indicate that perceived enjoyment plays an important role in shaping users' behavioural intention for both conventional and unconventional technologies. Implications for practice and future research are discussed.
\end{abstract}

\section{Introduction}

Computer technologies are very dynamic; they are constantly and rapidly evolving. They have become so ubiquitous in all aspects of life. It becomes challenging to think of a context that hasn't been transformed by computing technologies. Information technologies improve productivity in the workplace, help people connect and interact, and provides a medium for leisure and entertainment. The pervasiveness of many types of technologies makes their affordances predictable even to the unfamiliar user $[1,2]$. For example almost every software package, website, or information system artifact relies on a standardized graphical user interface with the same input/output device peripherals such as a pointing device, a keypad, or a touch screen. However, recent advancements in Information Technology research resulted in the development of unconventional artifacts, devices, and software packages that are nontraditional in nature; such as augmented and virtual reality artifacts, simulators, and robots. These emerging technologies are being introduced to address a variety of purposes such as improving scientific collaboration, entertainment, and care for the elderly $[2,3]$. It is thus imperative to assess our epistemology of user acceptance of technology and assess whether or not we can extend our theories to the realm of such unconventional artifacts.

Technology acceptance has been the holy grail of Information System (IS) research for decades. Several theories have been developed to explain and predict user acceptance of technologies, in a variety of contexts, such as TAM [4], UTAUT [5], ExpectationConfirmation Theories [6], Task-Technology Fit [7,8], Innovation Diffusion Theory $[9,10]$, and others. In most of these models, Behavioural Intention (BI) to use an artifact is widely operationalized as a dependent variable, and established as an important predictor of actual use, having roots in the Theory of Reasoned Action [11].

Technologies are generally categorized as either utilitarian in nature if they provide a productive outcome, or they are categorized as hedonic if they provide self-fulfilling values and experience to their users [12]. Many technologies are dual-purposed exhibiting a mixed utilitarian and hedonic nature. Extrinsic motivators to adopt a technology such as the users' perception of the artifact's usefulness have been extensively researched. Intrinsic motivators, on the other hand, have generally received less attention $[12,13]$, and are concerned with the users affective desire to use an artifact for no other outcome than its use per se [14]. For example, a recent meta-analysis by $\mathrm{Wu}$ and $\mathrm{Lu}$ [15] revealed that extrinsic motivator constructs have been studied at least three times as much as their intrinsic counterparts, and while extrinsic motivators are more valuable for utilitarian system studies, the study of intrinsic motivators is crucial for hedonic systems as well as dual-purposed systems. Perceived Enjoyment (PE) is regarded as the most 
salient intrinsic motivator, and has been repeatedly found to significantly influence BI for utilitarian artifacts, and even more so for hedonic systems [14,16-18]. However, researchers report conflicting results regarding the effect size of PE on BI [15].

The above discussion thus motivates this research endeavour with the following two overarching objectives:

1. Aggregate the findings regarding the effect size of PE of technology on the users' BI to use it across the literature.

2. Investigate how this effect of PE on $\mathrm{BI}$ is influenced by the conventionality of the technology.

To address these questions we conducted a metaanalytic review of the literature to cumulate research findings across empirical studies [19,20]. While the assessment and effects of intrinsic motivators, including PE, has been investigated in a recent metaanalysis [15], the studies included in that meta-analysis were limited to conventional technologies and software applications. Additionally, it covered a time range where research on unconventional technologies was still embryonic, and the emergence of cutting-edge novel and unconventional technologies was just beginning to blossom. Our objective thus is to include unconventional technology artifacts and to move beyond purely focusing on software artifacts to include unconventional hardware devices as well. To the best of our knowledge, there is no published research that includes such unconventional artifacts or makes this important conventionality distinction.

This investigation provides an indication regarding the appropriateness of extending our theories and models to emerging unconventional technologies, such as virtual reality, augmented reality, and robot technologies. Additionally, it sheds some light on the value and utility of assessing intrinsic motivation in the domain of technology adoption across utilitarian and hedonic contexts. This paper is organized as follows: we discuss the theoretical underpinnings that shape our proposed research framework in the next section; this is followed by a description of the methodology and the criteria used for sampling studies in section three; a discussion of the statistical synthesis and results in section four; the conclusions and implications for research and practice in section five; and finally, the limitations of the study and suggestions for future research are laid out in the last section.

\section{Theoretical background and research model}

In this investigation, we focus on the constructs of Perceived Enjoyment (PE), Behavioural Intention (BI), and Technology Conventionality (TC). The first two constructs are defined in the literature, while TC is not (Table 1 provides a summary of definitions). MerriamWebster defines unconventional as "very different from the things that are used or accepted by most people, not traditional, or usual.", and defines conventional as "common, ordinary, and of a kind that has been around for a long time and is considered to be usual or typical". We herein define TC as "the extent to which a technology conforms to standard humancomputer interfaces, traditional hardware designs, and typical technology affordances". For example, many virtual reality artifacts are unconventional because: they rely on innovative user interfaces (e.g., natural movements and mobility, gestures, and spoken commands instead of controllers and input peripherals); they have untraditional hardware designs (e.g., wearable headsets and sensors instead of standard displays); and atypical affordances (e.g., truly immersive user experiences).

The TC construct should not be confused with the construct of Familiarity $[21,22]$ which relates to the users' understanding and previous interaction with a technology. For example, technologies in the contexts of e-commerce, Internet and websites, e-banking, traditional online gaming, software packages,

Table 1: Definitions of Constructs of Focus

\begin{tabular}{|l|l|l|l|}
\hline Construct & Ref & Definition & Examples of measurement items \\
\hline $\begin{array}{l}\text { Perceived } \\
\text { Enjoyment }\end{array}$ & (PE) & $\begin{array}{l}\text { The degree to which the user deems } \\
\text { the technology use as a fun experience } \\
\text { regardless of outcome [14] }\end{array}$ & $\begin{array}{l}\text { I enjoy iCat talking to me } \\
\text { I found my visit to this website enjoyable }\end{array}$ \\
\hline $\begin{array}{l}\text { Behavioural } \\
\text { Intention }\end{array}$ & (BI) & $\begin{array}{l}\text { The strength of one's decisiveness to } \\
\text { use a certain technology in the future } \\
{[4]}\end{array}$ & $\begin{array}{l}\text { I'm planning to use iCat the next few days } \\
\text { I would consider using this website again in } \\
\text { the future }\end{array}$ \\
\hline $\begin{array}{l}\text { Technology } \\
\text { Conventionality }\end{array}$ & (TC) & $\begin{array}{l}\text { The extent to which a technology } \\
\text { conforms to standard human-computer } \\
\text { interfaces, traditional hardware } \\
\text { designs, and typical technology } \\
\text { affordances }\end{array}$ & $\begin{array}{l}\text { This technology utilizes an innovative user } \\
\text { interface, requires specialized hardware, and } \\
\text { enables atypical affordances (reverse coded) }\end{array}$ \\
\hline
\end{tabular}


enterprise resource planning, and other common workplace related technology artifacts are considered conventional. On the other hand, technologies requiring specialized hardware and enabling innovative affordances such as augmented reality, virtual reality, artificial/ambient intelligence artifacts and robots are considered unconventional. In both these categories, users can be either familiar or unfamiliar with the technology in question. This delineation is justified in the context of studying technology adoption because conventional technologies are pervasive and ubiquitous in nature their affordances are predictable. On the other hand, experience gained in learning to use one unconventional technology may not necessarily transcend to other paradigms, as each artifact can have its own unique affordances. The unconventionality and originality of the experience takes the user into an entirely different direction.

Given that some unconventional technologies are primarily hedonic [23,24] (e.g., conversation robots), primarily utilitarian $[3,25,26]$ (e.g., augmented meeting roundtable), or dual purposed [27,28] (e.g., virtual golf simulator), all these contexts are included in this investigation.

Motivation theory $[29,30]$ states that individuals are in constant active pursuit of satisfying various needs, and initiate behaviours to meet those needs. Motivation has been established by Self Determination Theory [31] as containing extrinsic and intrinsic components. Intrinsic motivation refers to an individual's incentive to initiate behaviour for its own merit because the experience satisfies some need [29] such as the need to enjoy and have fun. In IS, intrinsic motivation has been predominantly operationalized as PE [15] and has been shown to be predictive of individuals' BI to use a technology $[14,15,28]$. Thus we hypothesize that:

H1: Higher Perceived Enjoyment will positively influence Behavioural Intention to use a technology

Conventional technologies are by definition ubiquitous and mature [2], and thus for each given artifact it is safe to assume that there is at least one alternative artifact. For example several software packages perform the same functions, numerous websites provide information about a specific domain, multiple gaming consoles provide equivalent gaming experiences, and multiple online marketplaces provide very similar shopping experiences. Peripherals and input devices such as keyboards, mice, and touchscreens have not changed much in the past decade, and are standard across IS paradigms (e.g., laptops, medical equipment, tablets, mobiles, gaming consoles) and across brands competing in a specific domain (e.g., Windows PC, Apple Mac). With the availability of alternatives users can be more selective, thus in this context PE is expected to have a more profound effect on BI. On the other hand, unconventional technologies are still emerging and immature with limited pragmatic alternatives (e.g., surgical operation/aircraft simulators for students). Thus, it is expected that the effect of PE is less profound in the context of unconventional technologies and thus we propose the following:

P1: Technology conventionality will moderate the relation between $\mathrm{PE}$ and $\mathrm{BI}$ such that this relation will be stronger for conventional technologies compared to non-conventional ones.

Figure 1captures the above discussion outlining H1 and P1.

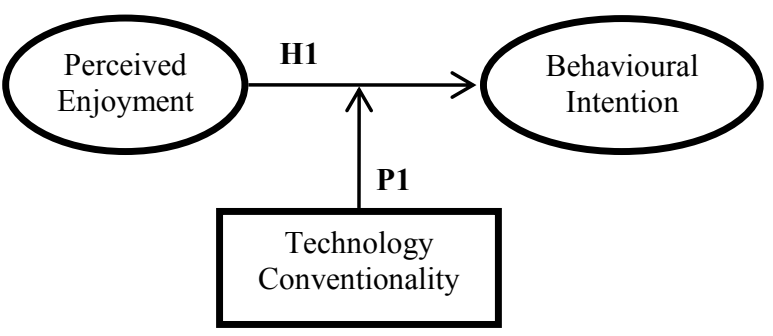

Figure 1: Proposed Research Model

\section{Methodology}

To test our research model and assess the strength of the effects, we conducted a meta-analysis of quantitative studies focusing on the constructs of interest. A meta-analysis is a particular form of a systematic literature review that focuses primarily on aggregating research findings across quantitative studies by applying statistical methods, following a deductive positivist approach $[19,20]$. We thus examined the technology acceptance literature in various relevant fields (e.g., IS, Marketing, Computer Science, Software and Applications, Information and Communication Technology, E-Commerce) for published research that includes any variation of our constructs of interest. Keywords, such as "Enjoyment and Intention", were utilized in online databases (e.g., Google Scholar, ProQuest, WebofScience) to find the constructs of interest in the extant and nascent literature. The authors have used personal judgement to assess the technologies examined in published research and code them into either the conventional or the unconventional category following the TC definition outlined above. A technology was categorized as 
unconventional if it was novel and out of the ordinary, if it was wearable, simulates a virtual reality for the user, augments reality by overlaying information to the user, utilizes artificial intelligence to autonomously interact with the user, or a combination thereof. The coding was performed independently, and the authors were in full agreement. While there is has been a surge of commercially available unconventional technologies in recent years [32], research investigating the acceptance of such unconventional technologies has a long history [33]. However, the rapid advancement in information technology and continuous innovations in processing and storage capabilities renders early prototypes used for studies obsolete, as they have far different affordances than their current mature and commercially available counterparts (e.g., VR devices in the 1980's occupied large rooms and the displays were monochromatic [33] offering a far less immersive experience), thus we limited our search to the period from 1990 to 2015. Bibliographies of existing work and bibliographic databases were utilized for backward and forward citations to find relevant studies. To reduce the effect of the file-drawer problem and publishing bias towards significant results in academic journals, proceedings of conferences in relevant domains (e.g., ICIS, AMCIS, HICSS, ECIS) and academic dissertations were also considered.

Studies were considered in our investigation on a case by case basis after carefully assessing the definitions and items used to measure the construct in question. We examined the items and measures of constructs that were suspect to be variations in the labeling/naming of our constructs of interests. For example Cyr et al. [17] examined the antecedents of eloyalty in an electronic commerce environment and used the conventional items of BI to measure the intention of users to use the website and shop again which they appropriately defined as e-Loyalty in their context, and thus it was included in our investigation. Similarly, Talal and Dennis [34] examined Continuance Intention which had an identical definition and measured by the same items, and thus the study was also included. On the other hand, studies that examined the relationship between PE and Attitude towards the artifact or Actual Use were excluded [35-38].
Overall, a total of 23 studies in 18 publications were included in our investigation (Table 2 provides a quick summary of the included studies). We hoped to achieve a balance between the conventional and unconventional technologies in terms of the studies selected and the number of participants included in those studies, but this proved difficult given the recency and high costs associated with unconventional technologies' research. While this can be a limitation, the meta-analytic procedure utilizing correlations effect size frees studies from sample size considerations and is appropriate in our context to study the relationship between two constructs [19].

The meta-analytic procedures used to aggregate the effect size (correlation coefficient) followed the Hunter and Schmidt approach [19,39]. For studies in which the correlation coefficients were not reported other statistical data were used to calculate it such as t-tests using online tools $[14,23,40]$. However, 6 studies in 5 publications were excluded because they did not provide sufficient information to calculate the correlation coefficient [38,41-44].

The meta-analytic procedures used to aggregate the effect size (correlation coefficient) followed the Hunter and Schmidt approach $[19,39]$. For studies in which the correlation coefficients were not reported other statistical data were used to calculate it such as t-tests using online tools $[14,23,40]$. However, 6 studies in 5 publications were excluded because they did not provide sufficient information Following the Hunter and Schmidt [39] approach coefficients were corrected for measurement errors by dividing by the square root of the reliabilities product [19]. For single item measures the reliability used was 1 [46]. Some studies only provided the lowest Cronbach alphas instead of a full listing and thus this value was used as a conservative estimate (e.g., [14,25,26]). Finally, some studies reported reliabilities in terms of Internal Consistencies Reliabilities (ICR) instead of Cronbach alphas e.g. [16,47] and thus these values were used since they are interchangeable without any significant deviations. Aggregate effect sizes were then calculated using a weighted mean after correcting for measurement error.

Table 2: Summary of Included Studies

\begin{tabular}{|l|r|r|r|r|r|r|r|}
\hline $\begin{array}{c}\text { Technology } \\
\text { Conventionality }\end{array}$ & $\begin{array}{c}\text { Number } \\
\text { of Studies }\end{array}$ & $\begin{array}{c}\text { Sample } \\
\text { Size }\end{array}$ & Mean r* & \multicolumn{1}{c|}{ Min } & Max & S.D & Outliers \\
\hline Unconventional & 8 & 748 & .4831 & .1902 & .746 & .1757 & 0 \\
\hline Conventional & $15^{* *}$ & 5,344 & .5255 & .2138 & .780 & .1844 & 0 \\
\hline Total & $23^{* *}$ & 6,090 & .5085 & .1902 & .780 & .1822 & 0 \\
\hline
\end{tabular}

*Note: Correlation Coefficients reported here are raw before any meta-analytic procedure ;

**4 studies by Nysveen et al. [45] are aggregated into $1, k$ values are thus reduced by 3 
We adopt the widely accepted heuristic developed by Cohen [48] regarding correlation effect size (e.g. small $=0.1$, medium $=0.25$, and large $=0.4$ ), as it is appropriate for making comparisons between independent groups across studies [19].

\section{Results}

Based on the findings (summarized in Table 3) we find support for $\mathrm{H} 1$ as the aggregate corrected mean effect size is large to very large, where almost $50 \%$ of the BI variance can be explained by $\mathrm{PE}$, with a $95 \%$ Confidence Interval of 0.677 to 0.733 (similarly, support for $\mathrm{H} 1$ holds true when examining the Unconventional and Conventional groups separately). Additionally, the Q statistic is significant at the $p<.01$ level indicating the heterogeneity of the population and the presence of moderators.

For our hypothesized moderator (P1), we metaanalyzed the conventional technology studies and unconventional technology studies separately and conducted a mean difference t-test (summarized in Table 4)

The results show a slight difference in the opposite to hypothesized direction that is not statistically significant. Additionally, it is worth noting that after accounting for TC, both levels of conventionality demonstrated significant population heterogeneity $(\mathrm{Q}$ in Table 3) indicating the presence of further moderators.

\section{Conclusions and implications}

It is apparent in both the hedonic and utilitarian contexts investigated in our analysis that $\mathrm{PE}$ has a large to very large effect size on BI. This can guide researchers in future investigations in giving the construct PE the attention it deserves. Additionally, this addresses the conflicting results in the literature regarding the impact of PE on BI by demonstrating an aggregated very large effect size across contexts.
PE is generally overlooked in many contexts especially when adoption is not voluntary $[14,15]$, the lack of presence of alternatives (e.g., when the user has no choice but to use the technology) justified this disregard of the importance of enjoyment. However, our findings concerning the lack of support for P1 provide evidence suggesting that $\mathrm{PE}$ is an important indicator of BI even in the absence of direct alternatives. For example, an employee might resist the dull technology with a pre-implementation substitute or other manual processes [49]. Thus, it is important to consider such intrinsic motivators in all contexts and even for utilitarian technologies and information systems. Developers and innovators of unconventional technologies should also consider the perceived enjoyment of their potential users of both hedonic and utilitarian systems and technologies.

\section{Limitations and suggestions for future research}

Several limitations have to be acknowledged. First, the nature of meta-analysis does not allow for the inclusion of qualitative findings that may be of value, for example two of the identified studies [37,42] used focus groups to identify the most important factors affecting BI in two different contexts (enterprise networks and e-commerce respectively) and in both cases users highlighted the importance of PE. While this was reflected in the surveys that were designed based on these findings, there is no pragmatic method to include such findings in our analysis. Second, many studies were excluded from our analysis for various reasons including the lack of focus on the PE construct or the lack of sufficient reported information to qualify the study for inclusion. We thus urge researchers, reviewers, and editors of academic journals to highlight the importance of including such results for replication and meta-analytic purposes. Third, the number of studies included in our analysis is not as high as aspired, thus more studies should be included by and identified through contacting researchers and

Table 3: Aggregated Corrected Results

\begin{tabular}{|c|c|c|c|c|c|c|}
\hline \multirow{2}{*}{$\begin{array}{c}\text { Technology } \\
\text { Conventionality }\end{array}$} & \multirow{2}{*}{ Mean $\mathrm{r}^{*}$} & \multirow{2}{*}{$\mathrm{r}^{2}$} & \multirow{2}{*}{$\mathrm{SE}$} & \multicolumn{2}{|c|}{$95 \% \mathrm{C} \mathrm{I}$} & \multirow{2}{*}{ Q } \\
\hline & & & & Lower & Upper & \\
\hline Unconventional & .7214 & .5204 & .048 & .6277 & .8151 & $33.0 * * *$ \\
\hline Conventional & .7030 & .4942 & .015 & .6736 & .7324 & $227.3 * * *$ \\
\hline Aggregate & 7047 & .4966 & .014 & .6766 & .7328 & $260.8 * * *$ \\
\hline
\end{tabular}


Table 4: Proposition Testing

\begin{tabular}{|c|c|c|c|c|c|c|c|c|c|}
\hline \multirow{2}{*}{$\begin{array}{c}\text { Technology } \\
\text { Conventionality }\end{array}$} & \multirow{2}{*}{ Нyp } & \multirow{2}{*}{$\mathrm{K}$} & \multirow{2}{*}{$\begin{array}{c}\text { Mean } \\
\mathrm{r}^{*}\end{array}$} & \multirow{2}{*}{$\begin{array}{c}\text { Mean } \\
\text { Difference } \\
(\mathrm{C}-\mathrm{U})\end{array}$} & \multicolumn{2}{|c|}{$95 \%$ C I } & \multirow{2}{*}{$\mathrm{T}$} & \multirow{2}{*}{$\mathrm{P}$} & \multirow{2}{*}{ Supported } \\
\hline & & & & & Lower & Upper & & & \\
\hline Uncon & \multirow{2}{*}{ P1 } & 8 & .7214 & \multirow{2}{*}{-.0184} & \multirow{2}{*}{-.0491} & \multirow{2}{*}{.0123} & \multirow{2}{*}{1.257} & \multirow{2}{*}{$.2249 * *$} & \multirow{2}{*}{ No } \\
\hline Conventional & & 12 & .7030 & & & & & & \\
\hline
\end{tabular}

*Corrected for measurement error

**Not significant

institutions for unpublished research, which will also aid even more in mitigating the file-drawer problem. Fourth, we acknowledge the difficulty in conducting research with emerging expensive and complex technologies which in turn affects the number of published findings in this domain. We hope that such important studies receive sufficient funding in the future to understand the implications of their use as early as possible. Finally, the heterogeneity of the findings after accounting for TC indicates the presence of further moderators. We suggest that future research should take into consideration multiple moderators, for example a two level TC by two level context (utilitarian and hedonic) research designs can provide insights regarding the effect size of PE in all possible combinations.

As a final note, we conclude our analysis by noting that our study provides evidence that the established technology acceptance theories are applicable to the realms of unconventional emerging technologies particularly given the lack of significant difference between the effect sizes of PE for both TC levels. Thus, future research can examine other antecedents of BI to assess their applicability in this domain as well.

Table 5: Studies Included in this meta-analysis

\begin{tabular}{|c|c|c|c|c|c|c|c|}
\hline $\mathbf{k}$ & Authors & $\mathbf{n}$ & $\mathbf{r}$ & $\begin{array}{c}\alpha \\
\mathbf{P E} \\
\end{array}$ & $\begin{array}{c}\alpha \\
\text { BI } \\
\end{array}$ & TC & Context \\
\hline 1 & $\begin{array}{l}\text { Cyr, D., Hassanein, K., Head, M., \& Ivanov, A. (2007). The role of social presence in } \\
\text { establishing loyalty in e-Service environments. Interacting with Computers, 19, 43-56. } \\
\text { doi:10.1016/j.intcom.2006.07.010 }\end{array}$ & 185 & 0.56 & 0.94 & 0.96 & $\mathrm{C}$ & $\begin{array}{c}\text { E- } \\
\text { Commerce } \\
\text { (Tickets) }\end{array}$ \\
\hline 2 & \multirow[t]{2}{*}{$\begin{array}{l}\text { Davis, F. D., Bagozzi, R. P., \& Warshaw, P. R. (1992). Extrinsic and intrinsic motivation to } \\
\text { use computers in the workplace. Journal of Applied Social Psychology, 22(14), 1111- } \\
\text { 1132. doi:10.1111/j.1559-1816.1992.tb00945.x }\end{array}$} & $200 *$ & 0.21 & 0.81 & 0.88 & $\mathrm{C}$ & $\begin{array}{l}\text { Word } \\
\text { Processing } \\
\text { SW }\end{array}$ \\
\hline 3 & & $80^{*}$ & 0.28 & 0.95 & 0.88 & $\mathrm{C}$ & $\begin{array}{l}\text { Graphics } \\
\text { SW }\end{array}$ \\
\hline 4 & $\begin{array}{l}\text { Heerink, M., Kröse, B., Wielinga, B., \& Evers, V. (2008). Enjoyment intention to use and } \\
\text { actual use of a conversational robot by elderly people. In 3rd ACM/IEEE International } \\
\text { Conference on Human Robot Interaction (pp. 113-120). doi:10.1145/1349822.1349838 }\end{array}$ & 30 & 0.42 & 0.84 & 0.95 & $\mathrm{U}$ & $\begin{array}{l}\text { Robotics } \\
\text { HW }\end{array}$ \\
\hline 5 & $\begin{array}{l}\text { Heijden, H. Van Der. (2004). User Acceptance of Hedonic Information Systems. MIS } \\
\text { Quarterly, 28(4), 695-704. doi:10.2307/25148660 }\end{array}$ & 1,144 & 0.59 & 0.86 & 0.87 & $\mathrm{C}$ & $\begin{array}{c}\text { Information } \\
\text { Website }\end{array}$ \\
\hline 6 & $\begin{array}{l}\text { Koufaris, M. (2002). Applying the Technology Acceptance Model and Flow Theory to Online } \\
\text { Consumer Behavior. Information Systems Research, 13(2), 205-223. }\end{array}$ & 280 & 0.62 & 0.94 & 1.00 & $\mathrm{C}$ & $\begin{array}{c}\text { E- } \\
\text { Commerce } \\
\text { (Books) }\end{array}$ \\
\hline 7 & $\begin{array}{l}\text { Agrawal, R., \& Karahanna, E. (2000). Time Flies When You're Having Fun: Cognitive } \\
\text { Absorption and Beliefs about Information Technology Usage. MIS Quarterly, 24(4), 665- } \\
\text { 694. }\end{array}$ & 288 & 0.56 & 0.93 & 0.97 & $\mathrm{C}$ & $\begin{array}{l}\text { Generic } \\
\text { Internet }\end{array}$ \\
\hline 8 & $\begin{array}{l}\text { Wu, J., \& Liu, D. (2007). The Effects of Trust and Enjoyment on Intention to Play Online } \\
\text { Games. Journal of Electronic Commerce Research, } 8(2), 128-140 \text {. }\end{array}$ & 253 & 0.78 & 0.93 & 0.96 & $\mathrm{C}$ & $\begin{array}{l}\text { Online } \\
\text { Games }\end{array}$ \\
\hline 9 & $\begin{array}{l}\text { Yi, M. Y., \& Hwang, Y. (2003). Predicting the use of web-based information systems: Self- } \\
\text { efficacy, enjoyment, learning goal orientation, and the technology acceptance model. } \\
\text { International Journal of Human Computer Studies, 59(4), 431-449. doi:10.1016/S1071- } \\
\text { 5819(03)00114-9 }\end{array}$ & 109 & 0.44 & 0.96 & 0.87 & $\mathrm{C}$ & E-Learning \\
\hline 10 & $\begin{array}{l}\text { Nysveen, H., Pedersen, P. E., \& Thorbjernsen, H. (2005). Intentions to Use Mobile Services: } \\
\text { Antecedents and Cross-Service Comparisons. Journal of the Academy of Marketing } \\
\text { Science, 33(3), 330-346. doi:10.1177/0092070305276149 }\end{array}$ & $\begin{array}{r}2,038 \\
* *\end{array}$ & 0.70 & 0.95 & 0.90 & $\mathrm{C}$ & $\begin{array}{l}\text { Mobile } \\
\text { Services }\end{array}$ \\
\hline 11 & $\begin{array}{l}\text { Moon, J. W., \& Kim, Y. G. (2001). Extending the TAM for a World-Wide-Web context. } \\
\text { Information and Management, 38(4), 217-230. doi:10.1016/S0378-7206(00)00061-6 }\end{array}$ & 152 & 0.26 & 0.96 & 0.88 & $\mathrm{C}$ & $\begin{array}{l}\text { Generic } \\
\text { Internet }\end{array}$ \\
\hline 12 & $\begin{array}{l}\text { Al-Maghrabi, T., \& Dennis, C. (2011). What drives consumers' continuance intention to e- } \\
\text { shopping?: Conceptual framework and managerial implications in the case of Saudi } \\
\text { Arabia. International Journal of Retail \& Distribution Management, 39(12), 899-926. } \\
\text { doi:10.1108/09590551111183308 }\end{array}$ & 465 & 0.78 & 0.94 & 0.96 & $\mathrm{C}$ & $\begin{array}{l}\text { E- } \\
\text { Commerce }\end{array}$ \\
\hline
\end{tabular}




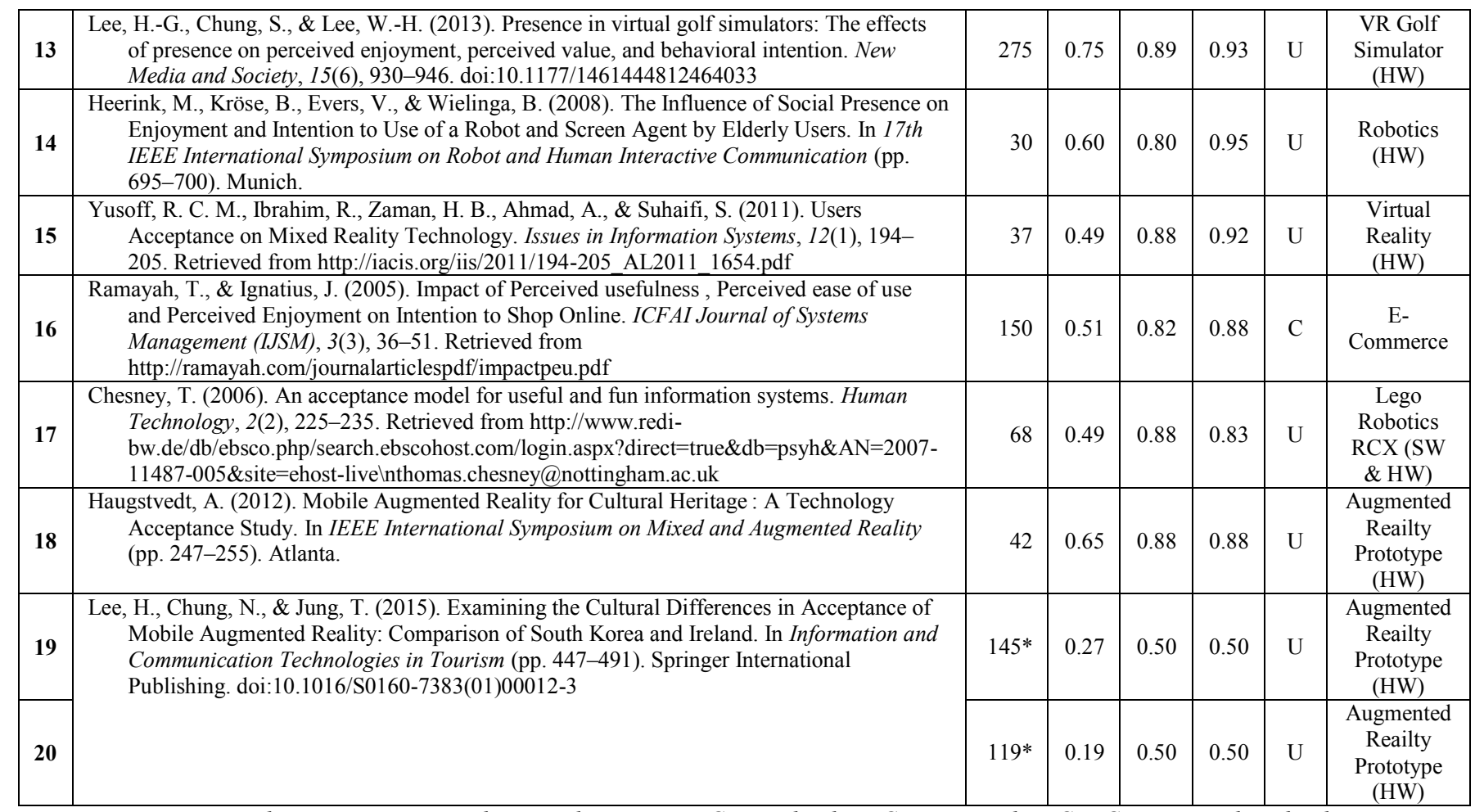

Notes: PE = Perceived Enjoyment, $B I=$ Behavioural Intention, $T C=$ Technology Conventionality, $C=$ Conventional Technology, $U=$ Unconventional Technology

*Separate studies treated separately

**Separate studies aggregated

\section{References}

[1] W.W. Gaver, Technology affordances, in: SIGCHI Conf. Hum. Factors Comput. Syst., 1991: pp. 7984. doi:10.1145/108844.108856.

[2] D.J. Cook, J.C. Augusto, V.R. Jakkula, Ambient intelligence: Technologies, applications, and opportunities, Pervasive Mob. Comput. 5 (2009) 277-298. doi:10.1016/j.pmcj.2009.04.001.

[3] T. Moeslund, M. Störring, Y. Liu, Towards natural, intuitive and non-intrusive hci devices for roundtable meetings, Multi-User Ubiquitous User Interfaces. (2004).

http://www.mmi.ifi.lmu.de/pubdb/publications/pu b/butz2004mu3iproc/butz2004mu3iproc.pdf\#page =31 (accessed February 26, 2015).

[4] F.D. Davis, R.P. Bagozzi, P.R. Warshaw, User acceptance of computer technology: a comparison of two theoretical models, Manage. Sci. 35 (1989) 982-1003.

http://www.jstor.org/stable/10.2307/2632151.

[5] V. Venkatesh, M.G. Morris, G.B. Davis, F.D.

Davis, User Acceptance of Information

Technology: Toward a Unified View, MIS Q. 27

(2003) 425-478. doi:10.2307/30036540.

[6] W.H. DeLone, E.R. McLean, The DeLone and McLean Model of Information Systems Success : A Ten-Year Update, J. Manag. Inf. Syst. 19 (2003)
9-30. doi:10.1073/pnas.0914199107.

[7] Y. Yuan, N. Archer, C.E. Connelly, W. Zheng, Identifying the ideal fit between mobile work and mobile work support, Inf. Manag. 47 (2010) 125137. doi:10.1016/j.im.2009.12.004.

[8] Ro.L. Thompson, Ch.A. Higgins, J.M. Howell, Personal Computing : Toward a Conceptual Model of Utilization, MIS Q. 15 (1991) 124-143. doi: $10.2307 / 249443$.

[9] F.C. Tung, S.C. Chang, C.M. Chou, An extension of trust and TAM model with IDT in the adoption of the electronic logistics information system in HIS in the medical industry, Int. J. Med. Inform. 77 (2008) 324-335. doi:10.1016/j.ijmedinf.2007.06.006.

[10] E. Karahanna, D.W. Straub, N.L. Chervany, Adoption Across Technology Information Time : a Cross-Sectional Comparison of, MIS Q. 23 (1999) 183-213.

[11] M. Fishbein, M. Fishbein, S.E. Middlestadt, S.E. Middlestadt, Using the theory of reasoned action to develop educational interventions: applications to illicit drug use, Health Educ. Res. 2 (1987) 361371.

[12] H. Van Der Heijden, User Acceptance of Hedonic Information Systems, MIS Q. 28 (2004) 695-704. doi:10.2307/25148660.

[13] H. Sun, P. Zhang, An Exploration of Affect 
Factors and Their Role in User Technology Acceptance: Mediation and Causality, J. Am. Soc. Inf. Sci. Technol. 59 (2008) 1252-1263.

[14] F.D. Davis, R.P. Bagozzi, P.R. Warshaw, Extrinsic and intrinsic motivation to use computers in the workplace, J. Appl. Soc. Psychol. 22 (1992) 1111-1132. doi:10.1111/j.15591816.1992.tb00945.x.

[15] J. Wu, X. Lu, Effects of Extrinsic and Intrinsic Motivators on Using Utilitarian, Hedonic , and Dual-Purposed Information Systems : A MetaAnalysis, J. Assoc. Inf. Syst. 14 (2013) 153-191.

[16] M.Y. Yi, Y. Hwang, Predicting the use of webbased information systems: Self-efficacy, enjoyment, learning goal orientation, and the technology acceptance model, Int. J. Hum. Comput. Stud. 59 (2003) 431-449. doi:10.1016/S1071-5819(03)00114-9.

[17] D. Cyr, K. Hassanein, M. Head, A. Ivanov, The role of social presence in establishing loyalty in eService environments, Interact. Comput. 19 (2007) 43-56. doi:10.1016/j.intcom.2006.07.010.

[18] R. Agrawal, E. Karahanna, Time Flies When You're Having Fun: Cognitive Absorption and Beliefs about Information Technology Usage, MIS Q. 24 (2000) 665-694.

[19] A.I. Huffcutt, Research Perspectives on MetaAnalysis, in: Handb. Res. Methods Ind. Organ. Psychol., Blackwell Publishers, Malden, MA, 2004: pp. 198-215.

[20] C. Okoli, K. Schabram, A Guide to Conducting a Systematic Literature Review of Information Systems Research, Work. Pap. Inf. Syst. 10 (2010) 1-51. doi:10.2139/ssrn.1954824.

[21] S.Y.X. Komiak, I. Benbasat, The Effects of Personalization and Familiarity on Trust and Adoption of Recommendation Agents, MIS Q. 30 (2006) 941-960. http://www.jstor.org/stable/25148760 \npapers3://p ublication/uuid/A07C0872-40C6-46BC-A728D76F691981B5.

[22] D. Gefen, E-commerce: the role of familiarity and trust, Omega. 28 (2000) 725-737. doi:10.1016/S0305-0483(00)00021-9.

[23] M. Heerink, B. Kröse, V. Evers, B. Wielinga, The Influence of Social Presence on Enjoyment and Intention to Use of a Robot and Screen Agent by Elderly Users, in: 17th IEEE Int. Symp. Robot Hum. Interact. Commun., Munich, 2008: pp. 695700.

[24] M. Heerink, B. Kröse, B. Wielinga, V. Evers, Enjoyment intention to use and actual use of a conversational robot by elderly people, in: 3 rd ACM/IEEE Int. Conf. Hum. Robot Interact., 2008: pp. 113-120. doi:10.1145/1349822.1349838.

[25] A. Haugstvedt, Mobile Augmented Reality for Cultural Heritage : A Technology Acceptance Study, in: IEEE Int. Symp. Mix. Augment. Real., Atlanta, 2012: pp. 247-255.

[26] H. Lee, N. Chung, T. Jung, Examining the Cultural Differences in Acceptance of Mobile
Augmented Reality: Comparison of South Korea and Ireland, in: Inf. Commun. Technol. Tour., Springer International Publishing, 2015: pp. 447491. doi:10.1016/S0160-7383(01)00012-3.

[27] T. Chesney, An acceptance model for useful and fun information systems., Hum. Technol. 2 (2006) 225-235. http://www.redi-

bw.de/db/ebsco.php/search.ebscohost.com/login.as px?direct $=$ true $\& \mathrm{db}=$ psyh \&AN=2007-11487005\&site $=$ ehost-

livelnthomas.chesney@nottingham.ac.uk.

[28] H.-G. Lee, S. Chung, W.-H. Lee, Presence in virtual golf simulators: The effects of presence on perceived enjoyment, perceived value, and behavioral intention, New Media Soc. 15 (2013) 930-946. doi:10.1177/1461444812464033.

[29] E.L. Deci, R.M. Ryan, The general causality orientations scale: Self-determination in personality, J. Res. Pers. 19 (1985) 109-134. doi:10.1016/0092-6566(85)90023-6.

[30] E.L. Deci, R.M. Ryan, The support of autonomy and the control of behavior., J. Pers. Soc. Psychol. 53 (1987) 1024-1037. doi:10.1037/00223514.53.6.1024.

[31] R.M. Ryan, E.L. Deci, Self-Determination Theory and the Facilitation of Intrinsic Motivation, Social Development, and Well-Being., Am. Psychol. 55 (2000) 68-78. doi:10.1037/0003-066X.55.1.68.

[32] M.E. Porter, J.E. Heppelmann, How Smart, Connected Products are Transforming Competition, Harv. Bus. Rev. (2014). https://hbr.org/2014/11/how-smart-connectedproducts-are-transforming-competition (accessed September 22, 2015).

[33] M.A. Gigante, Virtual reality: definitions, history and applications, Virtual Real. Syst. (1993) 3-14.

[34] T. Al-Maghrabi, C. Dennis, What drives consumers' continuance intention to e-shopping?: Conceptual framework and managerial implications in the case of Saudi Arabia, Int. J. Retail Distrib. Manag. 39 (2011) 899-926. doi:10.1108/09590551111183308.

[35] T.L. Childers, C.L. Carr, J. Peck, S. Carson, Hedonic and utilitarian motivations for online retail shopping behavior, J. Retail. 77 (2001) 511535. doi:10.1016/S0022-4359(01)00056-2.

[36] K. Hassanein, M. Head, The Impact of Infusing Social Presence in the Web Interface: An Investigation Across Product Types, Int. J. Electron. Commer. 10 (2006) 31-55.

[37] J. Kim, S. Forsythe, Adoption of virtual try-on technology for online apparel shopping, J. Interact. Mark. 22 (2008) 45-59. doi:10.1002/dir.20113.

[38] M. Atkinson, C. Kydd, Individual Characteristics Associated with World Wide Web Use: An Empirical Study of Playfulness and Motivation, Data Base Adv. Inf. Syst. 28 (1997) 53-62. doi:10.1145/264701.264705.

[39] J.E. Hunter, F.L. Schmidt, Methods of MetaAnalysis: Correcting error and bias in research findings, Sage, Newbury Park, CA, 1990. 
[40] J.W. Moon, Y.G. Kim, Extending the TAM for a World-Wide-Web context, Inf. Manag. 38 (2001) 217-230. doi:10.1016/S0378-7206(00)00061-6.

[41] K. Praveena, S. Thomas, Continuance Intention to Use Facebook: Role of Perceived Enjoyment and Trust, Int. J. Ind. Eng. Manag. Sci. 4 (2014) 2429. doi:10.9756/BIJIEMS.4794.

[42] A. Dickinger, M. Arami, D. Meyer, The role of perceived enjoyment and social norm in the adoption of technology with network externalities, Eur. J. Inf. Syst. 17 (2008) 4-11. doi:10.1057/palgrave.ejis.3000726.

[43] M. Conci, F. Pianesi, M. Zancanaro, Useful, social and enjoyable: Mobile phone adoption by older people, in: Human-Computer Interact., Springer Berlin Heidelberg, 2009: pp. 63-76. doi:10.1007/978-3-642-03655-2_7.

[44] D. Cyr, M. Head, A. Ivanov, Perceived Interactivity Leading to E-Loyalty: An Empirical Investigation of Web-Poll Design, in: Sixth Annu.
Work. HCI Res. MIS, Montréal, 2007: pp. 46-51.

[45] H. Nysveen, P.E. Pedersen, H. Thorbjernsen, Intentions to Use Mobile Services: Antecedents and Cross-Service Comparisons, J. Acad. Mark. Sci. 33 (2005) 330-346. doi:10.1177/0092070305276149.

[46] M. Koufaris, Applying the Technology Acceptance Model and Flow Theory to Online Consumer Behavior, Inf. Syst. Res. 13 (2002) 205-223.

[47] J. Wu, D. Liu, The Effects of Trust and Enjoyment on Intention to Play Online Games, J. Electron. Commer. Res. 8 (2007) 128-140.

[48] J. Cohen, A Power Primer, Psychol. Bull. 112 (1992) 115-159.

[49] M.-C. Boudreau, D. Robey, Enacting Integrated Information Technology: A Human Agency Perspective, Organ. Sci. 16 (2005) 3-18. doi:10.1287/orsc.1040.0103. 